\title{
PREDICTORS OF ASTHMA CONTROL IN PAEDIATRICS
}

D. BORDALO, J. FIGUEIRINHA, S. ROLIM, P. FONSECA, F. CARVALHO

Pediatrics / Neonatology Department - Centro Hospitalar Médio Ave - PORTUGAL

\section{BACKGROUND}

Asthma is the most frequent chronic disease in pediatrics with a rising incidence and prevalence in the last 30 years ${ }^{1-3}$

Physical activity (PA) is highly recommended in asthmatic patients in whom obesity and sedentary behaviour may contribute to worse disease control ${ }^{4-7}$

PA may reduce asthma symptoms by: increasing exercise tolerance and capacity inducing anti-inflammatory effects ${ }^{8}$

\section{AIMS and METHODS}

To describe predictors of asthma severity and control in children and adolescents with asthma

Cross-sectional study

3 months

Asthma + follow-up Paediatric medical appointments

Self-reported questionnaire: asthma control, sociodemographic information, physical activity patterns, and sedentary behaviour

\section{Descriptive Statistics}

Table 1 - Baseline characteristics of participants

\begin{tabular}{|ll} 
& frequency $(\%)$ \\
\hline Gender - boys & $82(71.9)$ \\
\hline BMI & $53(46.5)$ \\
$\quad$ Normal & $5(4.4)$ \\
Low & $20(17.5)$ \\
Excess & $36(31.6)$ \\
Obesity & \\
\hline
\end{tabular}

Triggers
Dust mites / Polen
$71(62.3)$

Sedentarism (screen time)

$>2$ hours/day $\quad 41$ (36)

1 hour/day

$34(29.8)$

Asthma control ${ }^{\S}$

well controlled

$58(50.9)$

uncontrolled

$13(11.4)$

Age - Median (IQR)

$12.5(10-15)$

$\mathrm{BMI}$ - body mass índex; IQR - interquartile range

${ }^{\S}$ According to GINA's level of asthma symptom control
RESULTS

\section{Inferential Statistics}

Number of participants $=114$

\section{8.}

Table 2 - Comparison of participants according to asthma control

\begin{tabular}{llll} 
& well controlled & uncontrolled & $p$-value \\
\hline Participants & & & \\
\hline $\begin{array}{l}\text { PA frequency } \\
\text { 4-5x/week }\end{array}$ & $66.7 \%$ & $12.1 \%$ & $0.003^{*}$ \\
\hline $\begin{array}{l}\text { PA duration } \\
60 \text { min/day }\end{array}$ & $56 \%$ & $18.8 \%$ & $0.015^{*}$ \\
\hline $\begin{array}{l}\text { Normal BMI } \\
\text { Inhaled corticosteroids }\end{array}$ & $58 \%$ & $12.5 \%$ & $0.034^{*}$ \\
\hline Parents & $7 \%$ & $0.041^{*}$ \\
\hline Non-smoking & $82.8 \%$ & 0 & \\
\hline PA & $53.4 \%$ & $5.2 \%$ & $0.031^{*}$ \\
\hline
\end{tabular}

Fisher's exact test

Higher parents' school level was associated with better asthma control No association found between sedentary behaviour and asthma control

\section{CONCLUSIONS}

The study provided indications that socio-demographic factors must be taken into account when prescribing physical activity in asthmatic patients

The findings are in accordance with previous reports that low PA may be associated with higher risk of uncontrolled asthma

Limitations: small sample size, non-parametric tests, parental assistance with the questionnaire, Berkson's bias, healthcare access bias, recall bias

An adequate asthma control strategy should weight the complexity of the family dynamics and involve all the stakeholders in order to improve disease outcomes

\section{CONTACT INFORMATION}

Diana Bordalo, diana.bordalo@gmail.com

Serviço de Pediatria do Centro Hospitalar do Médio Ave

Rua Cupertino de Miranda s/n Apartado 31

4761 - 917 Vila Nova de Famalicão (PORTUGAL)

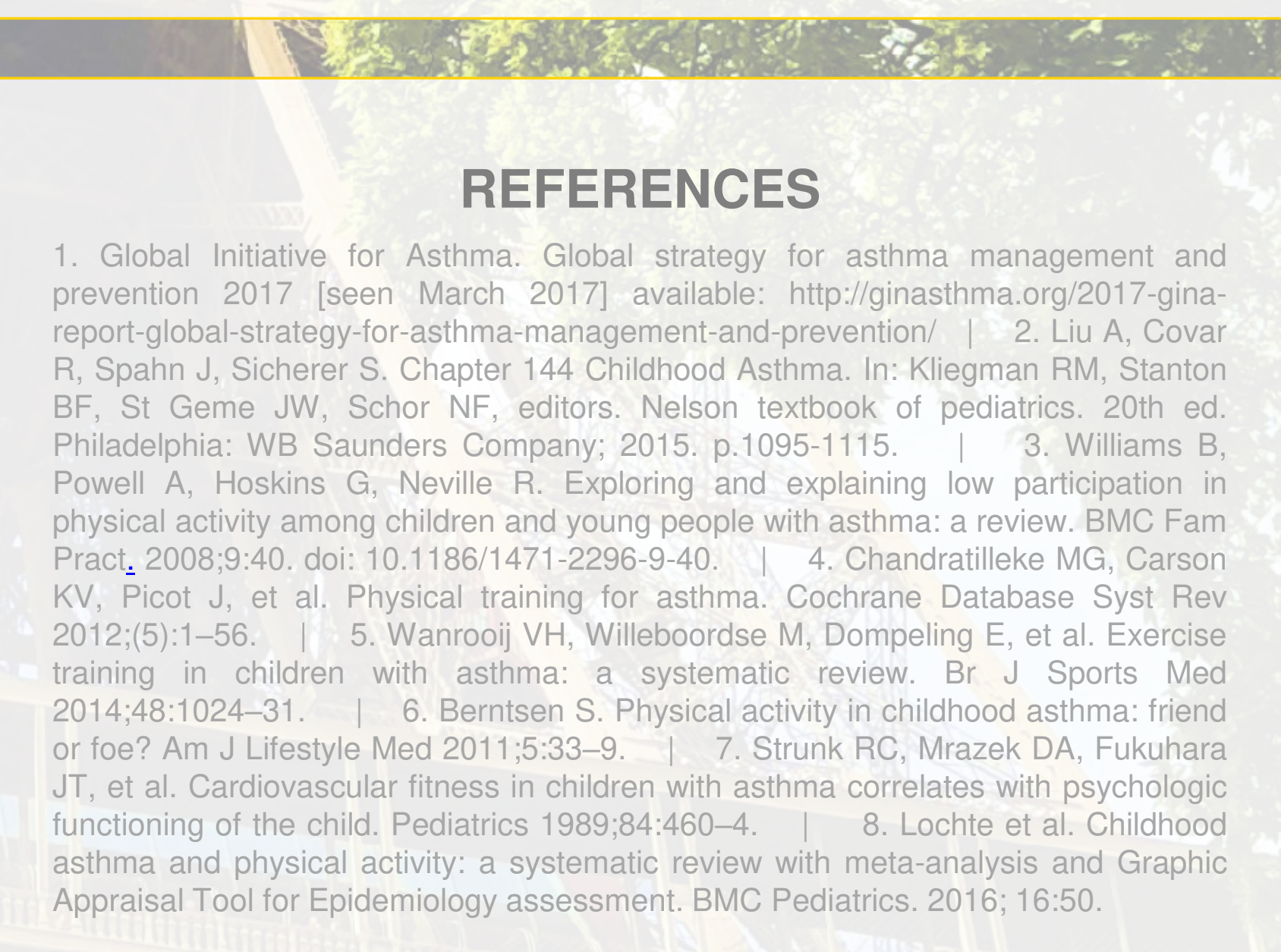

4 -

In relation to this presentation, I declare that there are no conflicts of interest 